\title{
Effect of posture on lung volume: airway closure and gas exchange in hemidiaphragmatic paralysis
}

\author{
H W CLAGUE AND D R HALL \\ Regional Cardio-Thoracic Centre, Broadgreen Hospital, Liverpool, UK
}

\begin{abstract}
The effects of posture on lung volume, airway closure, and gas exchange were studied in eight patients with hemidiaphragmatic paralysis. The mean vital capacity in the sitting position was $81 \%$ of predicted normal, and in the supine posture fell by a further $19 \%$ in right-sided but only $10 \%$ in left-sided paralysis. The mean arterial oxygen tension was less than predicted in the sitting posture and fell significantly on lying. Single breath gas transfer factor was normal in all cases whereas the diffusion coefficient was greater than predicted in the sitting posture and rose even further on lying. Closing volume showed no positional change but closing volume as a percentage of vital capacity was higher in the supine position. Regional airways closure was expressed as the relationship expiratory reserve volume minus closing volume. Negative values were found in only two of the subjects in the sitting position but seven had negative values supine, indicating significant airway closure during tidal breathing in this position.
\end{abstract}

Orthopnoea is a prominent symptom in many patients with diaphragmatic paralysis (McCredie et $a l, 1962)$ and hypoxia has also been observed in these patients when recumbent (Arborelius et al, 1975). We have examined airway closure in relation to this hypoxia and also studied the positional changes in overall lung function in hemidiaphragmatic paralysis unassociated with intrathoracic disease.

\section{Methods}

Eight patients (seven male, one female) were studied, and clinical details are summarised in table 1. The left hemidiaphragm was paralysed in four cases and the right in the other four. All were non-smokers at the time of the study. Two were lifelong non-smokers, while the other six had not smoked for at least 10 years. None had any evident intrathoracic cause for the phrenic paralysis, nor any other intrathoracic disease except for patient 7, who had mild bronchographically demonstrable bronchiectasis at the lung base on the affected side. Six complained of dyspnoea on effort, and four complained of orthopnoea, which had improved by the time of the study. There were no other respiratory symptoms, and all completed an MRC (1966) question- naire to exclude chronic bronchitis and to grade the severity of dyspnoea.

In every case the hemidiaphragm was raised considerably and showed paradoxical movement on sniffing.

Subjects were studied both sitting and supine. No measurements were made until ten minutes after the appropriate posture had been adopted. Arterial blood for gas analysis was always taken just before the closing volume estimation, which was done the same day as the overall lung function studies.

Lung volumes were measured by closed circuit helium dilution (Bates and Christie, 1950), helium concentrations being measured with a catharometer (Godart helium analyser). All volumes were recorded in litres and subsequently corrected to BTPS. The gas transfer factor was measured according to the single breath method of Ogilvie et al (1957). The diffusion coefficient was derived from the multiple breath estimation of alveolar volume.

Closing volumes were measured with radioactive ${ }^{133}$ xenon using the single bolus technique of Dollfuss et al (1966-7). Several determinations were made in both positions but only curves fulfilling the NHLI (1973) criteria of acceptibility were used. At least two estimations were acceptable in 
each position and a mean value was taken. The vital capacity measured during the estimation of closing volume was used when expressing closing volume as a percentage of vital capacity (CV/ VC $\%$ ). Values for forced vital capacity (FVC), slow vital capacity, and vital capacity measured during the closing volume estimation all agreed within $10 \%$ of each other.

Arterial blood gases were measured in a semiautomated blood gas analyser (IL413 blood gas analyser).

Predicted values for lung volumes, blood gases, gas transfer factor, and diffusion coefficient were taken from Cotes (1975). Predicted values for the relationship of closing volume to vital capacity $(\mathrm{CV} / \mathrm{VC})$ and expiratory reserve volume (ERVCV) were taken from McCarthy et al (1972) for the seven men and Buist and Ross (1973) for the woman.

\section{Results}

The lung function data for the two positions are summarised in tables 2 and 3. The vital capacity, which was $81 \%$ of the predicted value in the sitting position, showed the most consistent fall $(15 \%)$, and this was due mainly to the fall in expiratory reserve volume. The fall in vital capacity in the right-sided group was 19\% (SE 3.34) while that of the left-sided group was $10.25 \%$ (SE 0.85). This appeared to be a real difference achieving statistical significance at the $5 \%$ level. FVC behaved in a similar way to the slow vital capacity but the $\mathrm{FEV}_{1}$ fell by a slightly greater amount supine $\mathrm{N}$ so that $\mathrm{FEV}_{1} / \mathrm{FVC} \%$ also tended to be lower supine. $\mathrm{FEV}_{1} / \mathrm{FVC} \%$, however, remained close to the predicted value in both positions.

Total lung capacity and functional residual capacity were both reduced in the sitting position

Table 1 Clinical data on eight patients studied

\begin{tabular}{|c|c|c|c|c|c|c|c|c|}
\hline Patient & Age & Sex & $\begin{array}{l}\text { Weight } \\
(\boldsymbol{k g})\end{array}$ & $\begin{array}{l}\text { Height } \\
(m)\end{array}$ & Side affected & Smoking habits & $\begin{array}{l}\text { Suspected cause of } \\
\text { paralysed hemidiaphragm }\end{array}$ & $\begin{array}{l}\text { Current symptoms } \\
\text { MRC grade of } \\
\text { dyspnoea }\end{array}$ \\
\hline 1 & 64 & $\mathbf{M}$ & $78 \cdot 7$ & $1 \cdot 77$ & Left & $\begin{array}{l}\text { Ex-smoker } \\
13 \text { years } \\
\text { ( } 32 \text { pack years) }\end{array}$ & Idiopathic & $\begin{array}{l}\text { Grade } 2 \\
\text { dyspnoea. } \\
\text { Previous } \\
\text { orthopnoea }\end{array}$ \\
\hline 2 & 45 & $\mathbf{M}$ & $78 \cdot 0$ & $1 \cdot 78$ & Left & Non-smoker & $\begin{array}{l}\text { Cervical spondylosis } \\
\text { C 4, C } 5\end{array}$ & $\begin{array}{l}\text { Grade } 3 \\
\text { dyspnoea. } \\
\text { Mild orthopnoea }\end{array}$ \\
\hline 3 & 61 & $\mathbf{M}$ & $67 \cdot 0$ & $1 \cdot 68$ & Left & $\begin{array}{l}\text { Ex-smoker } \\
33 \text { years } \\
\text { ( } 6 \text { pack years) }\end{array}$ & $\begin{array}{l}\text { Idiopathic. } \\
\text { (Coincident left radial } \\
\text { nerve palsy) }\end{array}$ & $\begin{array}{l}\text { Grade } 2 \\
\text { dyspnoea }\end{array}$ \\
\hline 4 & 44 & $\mathbf{M}$ & $69 \cdot 2$ & $1 \cdot 73$ & Left & $\begin{array}{l}\text { Ex-smoker } \\
12 \text { years } \\
\text { (17 pack years) }\end{array}$ & Trauma & $\begin{array}{l}\text { Grade } 3 \\
\text { dyspnoea. } \\
\text { Orthopnoea }\end{array}$ \\
\hline 5 & 70 & $\mathbf{F}$ & $77 \cdot 0$ & $1 \cdot 63$ & Right & $\begin{array}{l}\text { Ex-smoker } \\
20 \text { years } \\
\text { ( } 33 \text { pack years) }\end{array}$ & $\begin{array}{l}\text { Herpes zoster of } \\
\text { C } 3, \text { C } 4, \text { C } 5\end{array}$ & $\begin{array}{l}\text { Grade } 3 \\
\text { dyspnoea. } \\
\text { Previous } \\
\text { orthopnoea }\end{array}$ \\
\hline 6 & 38 & $\mathbf{M}$ & $88 \cdot 9$ & $1 \cdot 77$ & Right & Non-smoker & Idiopathic & $\begin{array}{l}\text { Grade } 3 \\
\text { dyspnoea. } \\
\text { Previous } \\
\text { orthopnoea }\end{array}$ \\
\hline 7 & 71 & $\mathbf{M}$ & $70 \cdot 8$ & $1 \cdot 70$ & Right & $\begin{array}{l}\text { Ex-smoker } \\
10 \text { years } \\
\text { ( } 50 \text { pack years) }\end{array}$ & $\begin{array}{l}\text { Cervical spondylosis } \\
\text { C 3, C 4, C 5, C } 6\end{array}$ & Asymptomatic \\
\hline 8 & 41 & $\mathbf{M}$ & $68 \cdot 5$ & $1 \cdot 63$ & Right & $\begin{array}{l}\text { Ex-smoker } \\
10 \text { years } \\
\text { ( } 3 \text { pack years) }\end{array}$ & Trauma & Asymptomatic \\
\hline
\end{tabular}

Table 2 Lung volumes (litres BTPS)

\begin{tabular}{|c|c|c|c|c|c|c|c|c|c|c|c|c|}
\hline & \multicolumn{2}{|c|}{ Vital capacity $(l)$} & \multicolumn{2}{|c|}{$F E V_{1} / F V C \%$} & \multirow{2}{*}{\multicolumn{2}{|c|}{$\begin{array}{l}\text { Functional residual } \\
\text { capacity }(l)\end{array}$}} & \multicolumn{2}{|c|}{ Residual volume $(l)$} & \multirow{2}{*}{\multicolumn{2}{|c|}{$\begin{array}{l}\text { Total lung } \\
\text { capacity }(l)\end{array}$}} & \multicolumn{2}{|c|}{ Closing volume $(l)$} \\
\hline & \multirow{2}{*}{ Sitting } & \multirow{2}{*}{ Supine } & \multirow{2}{*}{ Sitting } & \multirow{2}{*}{ Supine } & & & \multirow{2}{*}{ Sitting } & \multirow{2}{*}{ Supine } & & & \multirow{2}{*}{ Sitting } & \multirow{2}{*}{ Supine } \\
\hline & & & & & Sitting & Supine & & & Sitting & Supine & & \\
\hline $\begin{array}{l}\text { Mean } \\
\pm \text { Standard error }\end{array}$ & $\begin{array}{l}3 \cdot 16 \\
0 \cdot 19\end{array}$ & $\begin{array}{l}2 \cdot 70 \\
0 \cdot 19\end{array}$ & $\begin{array}{l}72 \\
1 \cdot 63\end{array}$ & $\begin{array}{l}68 \\
3 \cdot 39\end{array}$ & $\begin{array}{l}2 \cdot 48 \\
0 \cdot 16\end{array}$ & $\begin{array}{l}2 \cdot 06 \\
0 \cdot 17\end{array}$ & $\begin{array}{l}1 \cdot 85 \\
0 \cdot 16\end{array}$ & $\begin{array}{l}1 \cdot 74 \\
0 \cdot 17\end{array}$ & $\begin{array}{l}5 \cdot 01 \\
0 \cdot 22\end{array}$ & $\begin{array}{l}4 \cdot 44 \\
0 \cdot 25\end{array}$ & $\begin{array}{l}0.53 \\
0.06\end{array}$ & $\begin{array}{l}0.54 \\
0.06\end{array}$ \\
\hline$P$ (paired $t$ test) & \multicolumn{2}{|c|}{$<0.001$} & \multicolumn{2}{|c|}{ NS } & \multicolumn{2}{|c|}{$<0.02$} & \multicolumn{2}{|c|}{ NS } & \multicolumn{2}{|c|}{$<0.001$} & \multicolumn{2}{|c|}{ NS } \\
\hline
\end{tabular}


Table 3 Arterial blood gases and diffusion indices

\begin{tabular}{|c|c|c|c|c|c|c|c|c|}
\hline & \multicolumn{2}{|c|}{$\mathrm{PAO}_{3}(\mathrm{kPa})$} & \multicolumn{2}{|c|}{$P A \mathrm{CO}_{2}(k P a)$} & \multicolumn{2}{|c|}{$\begin{array}{l}\text { Transfer factor } \\
\left(\mathrm{mmol} \mathrm{min}^{-1} \mathrm{kPa}^{-1}\right)\end{array}$} & \multicolumn{2}{|c|}{$\begin{array}{l}\text { Diffusion coefficient } \\
\left(\mathrm{mmol} \mathrm{min}^{-1} \mathrm{kPa}^{-1} \mathrm{~L}^{-1}\right)\end{array}$} \\
\hline & Sitting & Supine & Sitting & Supine & $\overline{\text { Sitting }}$ & Supine & Sitting & Supine \\
\hline $\begin{array}{l}\text { Mean } \\
\pm \text { Standard error } \\
\text { P (paired } t \text { test) }\end{array}$ & $\begin{array}{c}10 \cdot 1 \\
0.39\end{array}$ & $\begin{array}{l}9 \cdot 6 \\
0 \cdot 40\end{array}$ & $\begin{array}{l}4 \cdot 9 \\
0 \cdot 16\end{array}$ & $\begin{array}{l}5 \cdot 0 \\
0 \cdot 16\end{array}$ & $\begin{array}{l}8 \cdot 96 \\
2 \cdot 68\end{array}$ & $\begin{array}{l}9 \cdot 02 \\
2 \cdot 22\end{array}$ & $\begin{array}{l}2 \cdot 13 \\
0.40\end{array}$ & $2^{2 \cdot 44}$ \\
\hline
\end{tabular}

being $82 \%$ and $72 \%$ of the predicted value respectively. The fall in total lung capacity in the supine position mainly reflected the fall in vital capacity. Likewise the functional residual capacity was reduced further in the supine position by the fall in expiratory reserve volume. The residual volume did not alter with change in position being $90 \%$ of the predicted value when sitting.

Closing volumes were remarkably similar in the two positions so that the ratio of closing volume to vital capacity was consistently higher when patients were supine. If closing volume exceeds respiratory reserve volume the relationship ERV$\mathrm{CV}$ becomes negative and implies airway closure in the range of tidal breathing. ERV-CV was significantly reduced in the supine position, being negative in seven cases.

Arterial oxygen tension fell by a small but significant amount overall, but there was no alteration in the arterial tension of carbon dioxide. The mean value for the single breath transfer factor was normal sitting and changed little with posture in the group as a whole. The diffusion coefficient was consistently raised when sitting, the mean value being $139 \%$ of predicted, and rose by a further $15 \%$ when lying.

\section{Discussion}

A reduction in the vital capacity with a further fall in the supine position has been previously observed in both unilateral (Gould et al, 1967) and bilateral (Comroe et al, 1951; McCredie et al, 1962; Sandham et al, 1977) diaphragmatic paralysis. Gould showed a $14 \%$ reduction in the erect vital capacity and a further $21 \%$ fall on lying down in their group of subjects with artificially induced right-sided paralysis. Both the initial reduction and subsequent fall in recumbency is greater for total diaphragmatic paralysis, particularly when there is additional respiratory muscle weakness (Newsome Davis et al, 1976). This change in vital capacity with posture, $15 \%$ in the present study, is greater than the expected norm of about $3 \%$, and mainly results from reduced expiratory reserve volume. This is probably due to the inability of the paralysed hemidiaphragm to resist movement of the abdominal contents into the chest on lying down when gravitational forces have to be overcome. The significant difference in magnitude of fall between the two sides has not previously been noted and presumably reflects the greater liver mass on the right side. The figure of a $19 \%$ fall for the right-sided subjects in this study accords with the observations of Gould and others (1967), but there are no equivalent data for purely left-sided paralysis.

Changes in functional residual capacity and total lung capacity reflect the changes in vital capacity. Closing volume as a percentage of vital capacity tended to be less than predicted. Because of the reduction in expiratory reserve volume, however, the relationship ERV-CV was much less than predicted, being negative in seven subjects supine and in four even when sitting. A negative value for ERV-CV implies regional airway closure and less efficient gas exchange during normal tidal breathing and must partly explain the observed reduction in arterial oxygen tension in the two positions.

Overall hypoventilation as a cause for the hypoxia seems unlikely in view of the normal values for arterial carbon dioxide in both positions. Indeed hypoventilation and subsequent respiratory failure has been reported only for bilateral diaphragmatic paralysis (Newsom Davis et al, 1976). Furthermore, the supine fall in oxygen tension is not due to a change in the diffusion characteristics of the lung as the diffusion coefficient paradoxically rises in recumbency. Frans et al (1978) have recently concluded that in restrictive lung disease it is erroneous to express the diffusion coefficient as a function of predicted values established at total lung capacity. This probably accounts for the very high sitting values of diffusion coefficient when expressed as a percentage of the predicted values in the present study. On the other hand, the significant rise in the diffusion coefficient when lying indicates a real improvement in lung diffusion. This also occurs in normal subjects and has been attributed to the increased capillary blood volume and better apical matching of ventilation 
and perfusion in the supine position (Bates and Pearce, 1956).

Regional lung function studied with ${ }^{133}$ xenon radiospirometry in hemidiaphragmatic paralysis has shown the reduction in function at the lung base on the paralysed side. Arborelius et al (1975) showed the reduction to be least prominent supine and greatest sitting. However, the reduction in perfusion $(19 \%)$ and ventilation $(20 \%)$ in the sitting posture tended to be better matched than in the supine posture when perfusion was reduced by $9 \%$ and ventilation by $14 \%$. These authors found a postural drop in arterial oxygen tension and postulated that abnormal airway closure was the cause. Ridyard and Stewart (1976) in their study of paralysed hemidiaphragm in the supine position also found a greater reduction in ventilation than perfusion when compared to the normal side.

The small but significant fall in arterial oxygen tension found in this study confirms previous work, and our findings also suggest that abnormal airway closure might be responsible. The change in arterial oxygen tension is small, however, and the measurement of functional residual capacity, and therefore ERV-CV, too imprecise to allow a definite conclusion in such a small series of patients.

We thank Dr C M Ogilvie for his helpful comments and criticisms, Miss D Pollard, Mrs C Cummins, and Mrs L Stewart for technical help, the physicians and surgeons whose patients we studied, and Miss D Cousins who typed the final manuscript.

\section{References}

Arborelius, M, Lilja, B, and Senyk, J (1975). Regional and total lung function studies in patients with hemidiaphragmatic paralysis. Respiration, 32, 253264.

Bates, D V, and Christie, R V (1950). Intrapulmonary mixing of helium in health and in emphysema. Clinical Science, 9, 17-29.

Bates, D V, and Pearce, J F (1956). The pulmonary diffusing capacity; a comparison of methods of measurement and a study of the effects of body position. Journal of Physiology, 132, 232-238.

Buist A S, and Ross, B B (1973). Predicted values for closing volumes using a modified single breath nitro- gen test. American Review of Respiratory Disease, $\frac{\omega}{0}$ 107, 744-752.

Comroe, J H, Wood, F C, Kay, C F, and Spoont, $\frac{\bar{F}}{\bar{N}}$ E M (1951). Motor neuritis after tetanus antitoxin with involvement of the muscles of respiration. $\stackrel{\square}{\Omega}$ American Journal of Medicine, 10, 786-789.

Cotes, J E (1975). Lung Function, 3rd edn. Blackwell, Oxford.

Dollfuss, R E, Milic-Emili, J, and Bates D V (1966/7). Regional ventilation of the lung studied with ${ }_{\sigma}$ boluses of ${ }^{133}$ Xenon. Respiration Physiology, 2, 234 246.

Frans, A, Francis, C, Stanescu, D, Newery, J, $\underset{\oplus}{\omega}$ Prignot, J, and Brasseur, L (1978). Transfer factor $A$ in patients with emphysema and lung fibrosis. if Thorax, 33, 539-540.

Gould, L, Kaplan, S, McElhinney, A J, and Stone, 옹 D J (1967). A method for the production of hemi- diaphragmatic paralysis. American Review of Respiratory Disease, 96, 812-814.

McCarthy, D S, Spencer, R, Greene, R, and Milic- $\frac{\complement^{\circ}}{}$ Emili, J (1972). Measurement of "closing volume" as a simple and sensitive test for early detection of $\overrightarrow{0}$ small airway disease. American Journal of Medicine, 52, 747-753.

McCredie, M, Lovejoy, F W, and Kaltreider, N L (1962). Pulmonary function in diaphragmatic paralysis. Thorax, 17, 213-217.

Medical Research Council, Committee on Research $\stackrel{2}{\circ}$

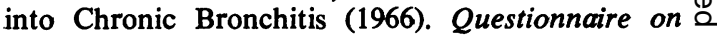
Respiratory Symptoms. MRC, London.

National Heart and Lung Institute (1973). Suggested Standard Procedures for Closing Volume Determinations (Nitrogen Method). Government Printing Office, Washington.

Newsom Davies, J, Goldman, M, Loh, L, and Casson, M (1976). Diaphragm function and alveolar hypoventilation. Quarterly Journal of Medicine, 45, 87100.

Ogilvie, C M, Forster, R E, Blakemore, W S, and Morton, J W (1957). A standardised breath- $O$ holding technique for the clinical measurement of the diffusing capacity of the lung for carbon mon- 은 oxide. Journal of Clinical Investigation, 36, 1-17.

Ridyard, J B, and Stewart, R M (1976). Regional lung function in unilateral diaphragmatic paralysis. Thorax, 31, 438-442.

Sandham, J D, Shaw, D T, and Guenter, C A (1977). N Acute supine respiratory failure due to bilateral N diaphragmatic paralysis. Chest, 72, 96-98.

Requests for reprints to: Dr H W Clague, Department of Thoracic Medicine, Fazakaley Hospital, Lower $\stackrel{\mathcal{Q}}{\rightarrow}$ Lane, Liverpool L9 7AL. 